\title{
Blindness to institutional betrayal by the APA
}

We incorrectly called the American Psychological Association the American Psychology Association in this Letter (BMJ 2015;351:h4172, doi:10.1136/bmj.h4172).
Cite this as: BMJ 2015;351:h4355

๑) BMJ Publishing Group Ltd 2015 